\title{
LONG-TERM CONSUMPTION AND FOOD REPLACEMENT OF NEAR-ISOGENIC BY BT-MAIZE ALTER LIFE-HISTORY TRAITS OF FOLSOMIA CANDIDA WILLEM 1902 (COLLEMBOLA)
}

\author{
SZABÓ, B.-SERES, A.-BAKONYI, G. ${ }^{*}$ \\ Szent István University, Department of Zoology and Animal Ecology \\ Páter K. u. 1. 2100 Gödöllö, Hungary \\ (phone: +36-28-522-000; fax: +36-28-410-804) \\ *Corresponding author \\ e-mail: bakonyi.gabor@mkk.szie.hu \\ (Received $2^{\text {nd }}$ May 2017; accepted $17^{\text {th }}$ July 2017)
}

\begin{abstract}
The long-term effect of Bt-maize on soil animals is an important, repeatedly discussed, but a poorly investigated topic. The collembolan Folsomia candida is a recognised representative of the mesofauna in the laboratory ecotoxicological experiments. The following questions were addressed in the present experiment: (i) is there any consequence on some life-history traits of $F$. candida, if Bt-maize is provided as food after about 4 years of feeding instead of the near-isogenic counterpart, and (ii) is there any effect on life-history traits, if the near-isogenic and Bt-toxin containing food is changed? Long-term (40-48 generations) feeding on Bt-maize leaf caused alterations in some life-history traits (larger eggs, higher growth rate both in length and width). On the other hand, reproduction (egg size, the total number of eggs, the number of eggs in the first clutch) was influenced, if Bt-toxin containing maize was replaced by its near-isogenic counterpart. Based on currently available methodologies, it is not possible to judge, whether observed differences are due to the Bt-toxin or another component of the maize leaf.
\end{abstract}

Keywords: MON810 maize; CrylAb toxin; egg size; body growth; sublethal effect

\section{Introduction}

Genetically engineered (GM) crops are cultivated on 179.7 million hectares all over the world from which maize plants are planted on 53.9 million hectares (James, 2015). Side effects of GM plants on soil animals have been studied both in the field as well as laboratory experiments in numerous cases. The results of the field experiments are summarised e.g. by Birch et al. (2007) and currently by Arias-Martín et al. (2016). In general, no severe side-effects on soil animal (Zwahlen et al., 2007; Hönemann et al., 2008) or collembolan (Marvier et al., 2007; Comas et al., 2014) populations and coenosees were found in the field.

Laboratory experiments were performed with GM plants and several non-target soil animal species, like earthworms, woodlouse, nematodes, collembolan, etc. Collembolans occupy a substantial position in plant litter decomposition processes, forming soil microstructure and regulating microbial species composition and biomass (Bakonyi, 1989; Rusek, 1998). That is why collembolan species are used in the laboratory for soil biological studies. The most frequently employed species of them is Folsomia candida Willem 1902 (Fountain and Hopkin, 2005). This species have been often in the focus of ecotoxicological studies as well as when the side-effects of the GM plants is examined (Jepson et al., 1994). Besides, this species is recommended as a representative of decomposers, if GM plant and/or Bt-protein effect on non-target organisms is investigated (Römbke et al., 2010; De Schrijver et al., 2016). 
Studying the side-effects of the GM plants on $F$. candida, short-term laboratory studies were conducted in most cases. Tested material included purified toxin as well as different plant parts as pollen, stalk, root or leaf. Their effects were investigated on different life-history traits of $F$. candida, as mortality, reproduction, and growth.

Four Bt-toxins (Cry1Ab, Cry1Ac, Cry2A, Cry3A) presented in the diet (mixed with Baker's yeast) did not influence adult mortality and the number of juveniles of $F$. candida (Sims and Martin, 1997). Similarly, in a dietary exposure assay, Cry1C and Cry2A toxin did not influence either the survival, and development of the animals, nor the measured antioxidant-, detoxification-, and digestion-related enzyme activities (Yang et al., 2015). However, Broza et al. (2001) found decreased reproduction if $F$. candida was fed on B. thuringiensis diet.

Yu et al. (1997) studied the effect of the Bt-toxin (Cry1Ab and Cry1Ac) producing cotton on oviposition time, the number of eggs, and final body lengths of the $F$. candida, but the measured traits remained unaffected. Romeis et al. (2003) did not find differences in mortality, clutch size, body weight and duration of egg development when $F$. candida was fed on the KP4-transgenic wheat plant (Golin and Greina varieties) and its near-isogenic counterpart. The effects of Bt and near-isogenic lines of rice were studied in two laboratory experiments. In the first one, Bai et al. (2011) used two Cry1Ab containing Bt-rice lines and their near-isogenic counterpart as food. Growth, reproduction, and superoxide dismutase activity were unaffected both in the Petri-dish and soil microcosm experiment. In the second study, root, stem, and leaf of three Bt and non-Bt-rice were provided as food and survival, reproduction and growth as traits were measured (Yuan et al., 2013). Differences in the measured traits between the treatments were not observed in these two studies.

Regarding the effect of the GM maize consumption on $F$. candida, few studies were published till now. Comparing the effects of near-isogenic and Bt-maize (Bt11 and MON810 varieties), no significant differences were detected as a consequence of feeding on Bt-maize in mortality and offspring number by Clark and Coats (2006). Bakonyi et al. (2006) observed about 30\% less fecal pellets around the Bt-maize (MON810) than its near-isogenic counterpart. Recently, Zhang et al. (2017) found no effect of Cry1Ab/Cry2Aj toxin contained maize pollen on $F$. candida survival, development, and reproduction.

As presented above, several short-term experiments with $F$. candida exist, but longterm laboratory studies are scarce. As far as we know, no other research group as ours is working in this research field. In a previous study (Bakonyi et al., 2011) no effect of Btmaize (MON810) on egg production and food choice of $F$. candida was found if the animals were fed up to 29 months with this plant leaves. Working under similar experimental circumstances as in the mentioned study, the following questions were addressed in the present study: (i) is there any consequence on life-history traits of $F$. candida, if Bt maize is provided as food after about 4 years (40-48 generations) of feeding instead of the near-isogenic counterpart, and (ii) is there any effect on lifehistory traits, if the food is changed, e.g. near-isogenic maize line is provided after feeding on Bt-maize for 4 years? It was hypothesized that (i) long-term feeding has an impact on life-history traits, because of the different quality of the $\mathrm{Bt}$ and near-isogenic plants and (ii) a shift due to the food change will appear in life-history traits of $F$. candida, because this species preferred near-isogenic maize leaves in a previous experiment (Bakonyi et al., 2006). 


\section{Material and Methods}

Folsomia candida Willem 1902 (Collembola, Isotomidae) used in this study was obtained from the stock population reared in the laboratory of the Szent István University, Department of Zoology and Animal Ecology, Gödöllö (Hungary) since about 20 years. Our animals are belonging to the clade B according to the grouping by Tully et al. (Tully et al., 2006). Collembolans were kept in Petri dishes of a diameter 9 $\mathrm{cm}$ based on the method of Goto (1960). Animals in stock culture were kept at a temperature of $20 \pm 0.2{ }^{\circ} \mathrm{C}$, with constant humidity $(\sim 100 \%)$ and in total darkness. Dry baker's yeast was given as food ad libitum once a week.

This experiment was started with two stock populations. One of them was fed with MON810 (YieldGard $\AA$ ) maize line and the second one with its near-isogenic counterpart (variety DK-440). Both groups of collembolans were fed with ground leaf of these maize varieties for 4 years. Maize leaves of similar size and position on the plant were collected at harvest than stored dried, in a dark, cool place. Since the embryonic development of our animals takes about 8-10 days, and they arrive their sexual maturity in 10-12 days, its generation time is calculated as roughly one month. Consequently, 1012 generation per year as a conservative estimation was used for calculating the total number of generations under conditions of our laboratory.

Ground leaf litter was presented as food ad libitum and two grains of baker's yeast to arrange balanced nutrition of the animals. Nitrogen and carbon content of the maize leaf was as follows: $\mathrm{N} \% 0.27 \pm 0.02$ and $0.29 \pm 0.03$ and $\mathrm{C} \% 41.9 \pm 4.2$ and $40.5 \pm 4.5$ for isogenic and Bt-maize, respectively. Cry1 Ab concentration was $8.38 \pm 0.19 \mu \mathrm{g} / \mathrm{g}$ dry leaf material, which is in the range presented by Székács et al. (2010). Leaf of MON810 used in this study contained higher Cry1 Ab concentration, in comparison with root, stem, anther wall and pollen (Székács et al., 2010).

The experiment was performed with 10-12 days old synchronised $F$. candida individuals. Every treatment of the collembolans was started with 50 animals. They were kept in $5 \mathrm{~cm}$ high plastic dishes (the base $5.3 \mathrm{~cm}$ and the top $6.6 \mathrm{~cm}$ in diameter). Two $\mathrm{cm}$ of the mixture of active carbon and plaster of Paris was layered on the bottom in a ratio of 1:10. The top of the wet mixture was scrubbed to arrange smooth surface without holes. The animals were kept individually. Each collembolan got a unique identification number. The experimental animals were kept in total darkness, at a temperature of $20 \pm 0.2{ }^{\circ} \mathrm{C}$ and with constant humidity $(\sim 100 \%)$. The length of the experiment was 29 days.

Four treatments were set up in the experiment, as follows:

- IsoIso treatment: collembolans consumed the near-isogenic maize (DK-440) for 4 years before the experiment and during the experiment, as well.

- IsoBt treatment: collembolans consumed the near-isogenic maize (DK-440) for 4 years, but MON810 maize during the experiment.

- BtBt treatment: collembolans consumed MON810 maize for 4 years before the experiment and during the experiment, as well.

- BtIso treatment: consumed MON810 maize for 4 years, but near-isogenic maize (DK-440) during the experiment.

Following traits were measured in this study: 1.) final length $(\mathrm{mm}), 2$.) length growth rate, 3.) final width $(\mathrm{mm}), 4$. width growth rate, 5.) number of eggs in the first clutch, 6.) days till first clutch, 7.) total No. of eggs, 8.) No. of eggs/clutch, 9.) egg size (mm). 
Digital photos were taken from each animal twice a week from 4 to 29 days (Olympus C7070 Wide zoom camera with Olympus C5060 ADL optic). The length of the animals was measured from the frons to the end of the last segment, while the width at the widest part of the metathorax. The length and width for any collembolan at a given time were calculated as the mean of measurements on two consecutive photos to avoid inaccuracy which may cause of collembolan movements. Final body length and width, as well as growth rate, were calculated with the CurveExpert 1.4 software for any animals (Hyams, 2010). The equation Exponential Association $\left(y=a\left(1-e^{\wedge}-b x\right.\right.$; where a $=$ final value of length or with; $b=$ growth rate) was applied. Only those animal's data were regarded which survived until the end of the experiment.

The egg clutches were transferred to Petri dishes which contained a $0.5 \mathrm{~cm}$ high mixture of active carbon and plaster of Paris $(1: 10)$ on the bottom. The clutches were spread carefully with a wet brush in order to separate eggs from each other and digital photo was taken from them (BTC STM-9T microscope equipped with MicroQ-PRO type camera). The eggs were numbered on the photo. After that, an egg was chosen randomly from all of the clutches. The shortest and longest diameters of the eggs relative at a $90^{\circ}$ angle to each other were measured with the aid of the ImageJ software (Schneider et al., 2012). Egg diameters were transformed so that the two diameters were multiplied by each other and the square root of it was extracted, so it gives a diameter as the egg were perfectly round (TD = egg size, hereafter). Egg numbers and the date of egg laying were monitored continuously every day during the experiment.

Final length, length growth rate, final width and width growth rate were compared with ANOVA. If the significant effect was found $(\mathrm{p}<0.05)$ than posthoc BonferroniHolm test was applied. Effect of treatment on a total number of eggs, the number of eggs in the first clutch, days till the first clutch, the number of eggs/clutch and egg size (TD) was analysed with linear models. The mortality of the animals was analysed with a binomial model (R Core Team, 2012).

Canonical Variate Analysis (CVA) was performed based on the measured traits (the trait "days till the first clutch" was not applied because data distribution was not normal despite transformation). The SynTax2000 statistical program package (Podani, 1993) was used for the analysis.

\section{Results}

\section{Long-term feeding effect}

At the start of the experiment the body length and width of the 10-12 day old collembolan were significantly different between the treatments $(\mathrm{t}=3.9$, df $=46, \mathrm{p}<$ 0.001 and $\mathrm{t}=2.8$, $\mathrm{df}=46 \mathrm{p}<0.01$, for body length and width, respectively). Growth curves of both length (Figure 1) and width (Figure 2) showed sigmoid shape type. Measured points fitted well to the curve because correlation coefficients of the fitting were 0.95 or higher in cases of all individuals. Final body length and width of the IsoIso and BtBt animals did not differ significantly from each other (Table 1). The length and width of the collembolans ranged from 0.426 to $2.238 \mathrm{~mm}$ and 0.080 to 0.583 , respectively (data of all treatments). The relationship between body length and width may describe with the equation as follows: width $(\mathrm{mm})=0.27 *$ length $(\mathrm{mm})-0.047(\mathrm{r}=$ $0.95, \mathrm{t}=88.4$, df $=1161, \mathrm{p}<0.001)$. No treatment-related differences in body length and width relationship were found. Growth rates correlated negatively with both final body length $(\mathrm{r}=0.73, \mathrm{t}=10.6, \mathrm{df}=99, \mathrm{p}<0.001)$ and width $(\mathrm{r}=0.71, \mathrm{t}=10.0, \mathrm{df}=99$, 
$\mathrm{p}<0.001)$. This relationship is seen very clearly in Figure 3. as well. Egg size and a total number of eggs did not correlate each other.

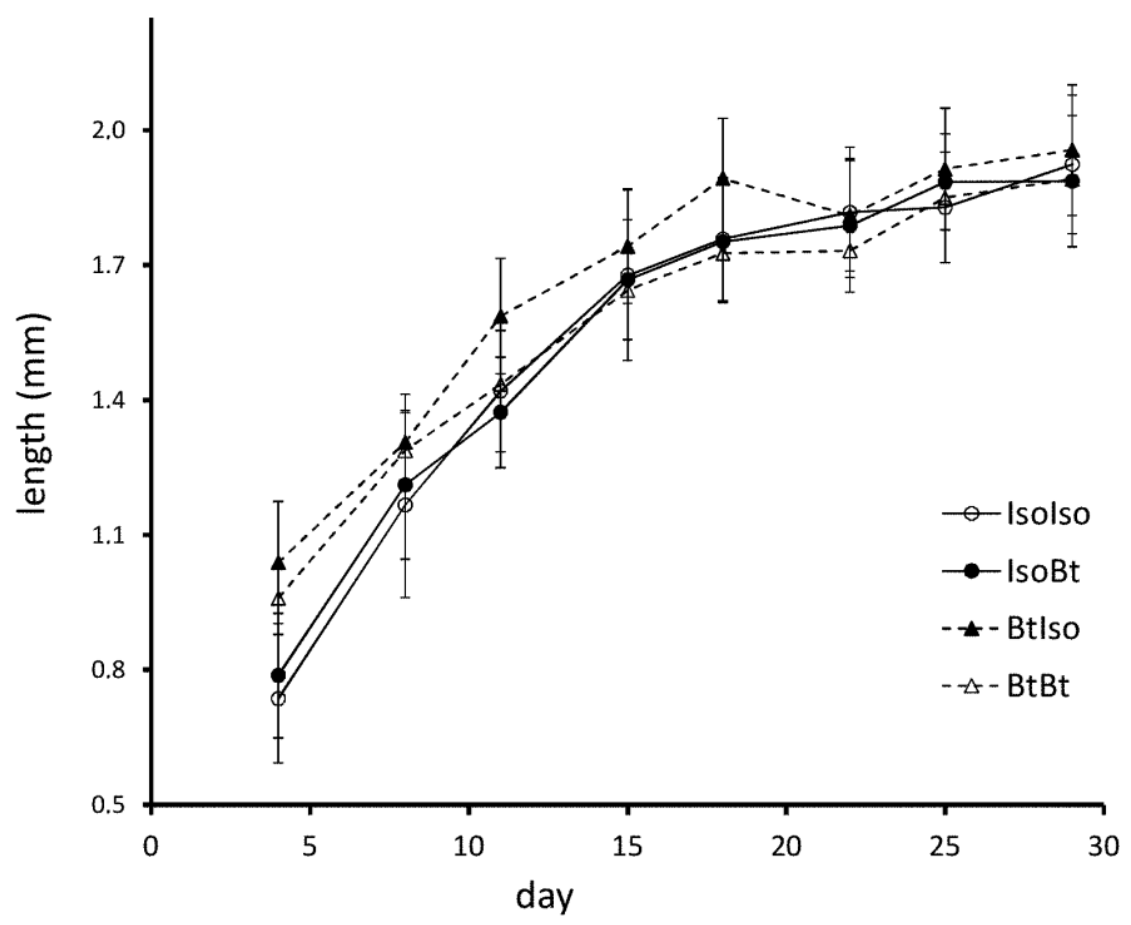

Figure 1. Body length growth (average $\pm S D$ ) of $F$. candida in the four treatments during the experiment.

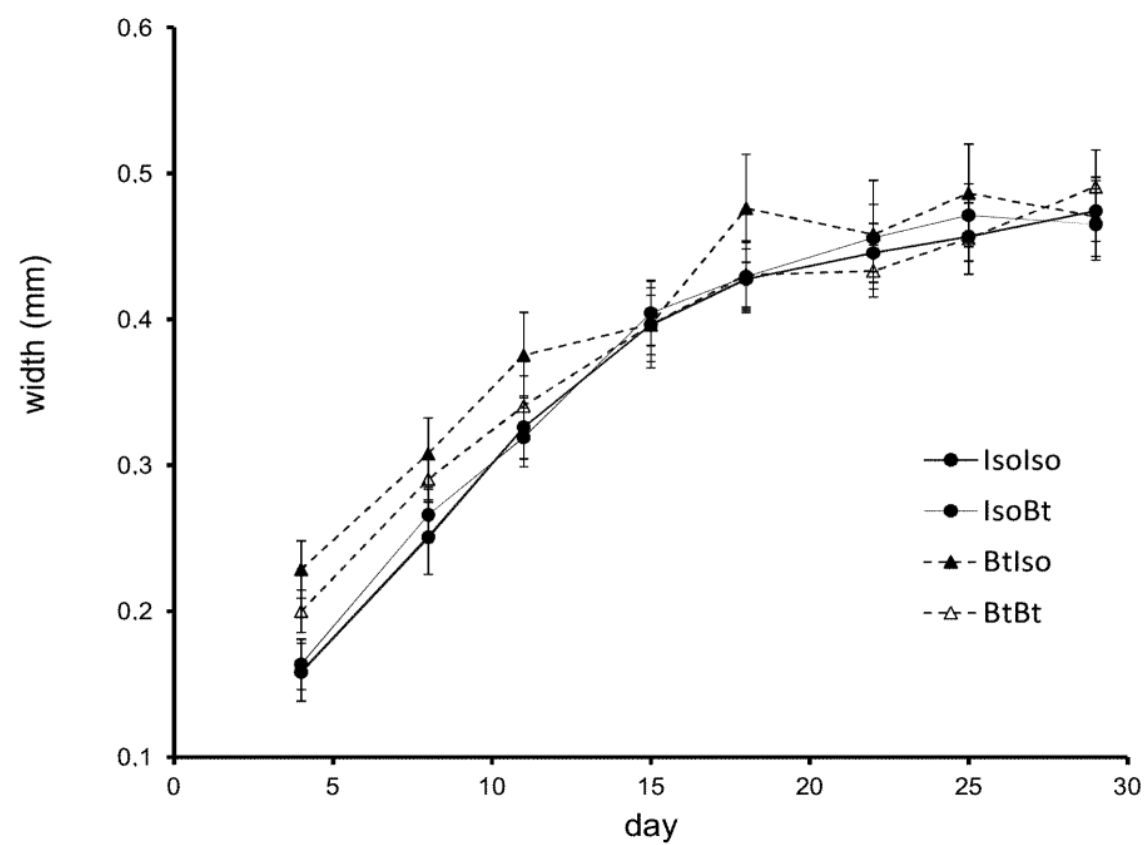

Figure 2. Body width growth (average $\pm S D$ ) of $F$. candida in the four treatments during the experiment. 
Table 1. Average $( \pm S D)$ of the measured traits. Means in a row followed by the same letter are not significantly different $(p<0.05)$.

\begin{tabular}{lllll}
\hline & IsoIso & IsoBt & BtBt & BtIso \\
\hline Final length (mm) & $1.99 \pm 0.18$ & $1.97 \pm 0.16$ & $1.92 \pm 0.19$ & $1.95 \pm 0.12$ \\
Length growth rate & $0.13 \pm 0.04^{\mathrm{a}}$ & $0.12 \pm 0.02^{\mathrm{a}}$ & $0.16 \pm 0.05^{\mathrm{b}}$ & $0.17 \pm 0.05^{\mathrm{b}}$ \\
Final width (mm) & $0.53 \pm 0.05$ & $0.54 \pm 0.07$ & $0.51 \pm 0.09$ & $0.5 \pm 0.05$ \\
Width growth rate & $0.1 \pm 0.03^{\mathrm{a}}$ & $0.09 \pm 0.03^{\mathrm{a}}$ & $0.12 \pm 0.04^{\mathrm{b}}$ & $0.14 \pm .04^{\mathrm{b}}$ \\
No. eggs in first clutch & $52.7 \pm 41.4$ & $31.0 \pm 24.0$ & $33.9 \pm 28.6$ & $28.9 \pm 24.1$ \\
Days till the first clutch & $15.3 \pm 5.0$ & $14.1 \pm 3.3$ & $13.6 \pm 4.8$ & $13.8 \pm 5.3$ \\
Total No. of eggs & $131.0 \pm 53.1$ & $111.8 \pm 41.2$ & $144.5 \pm 93.4$ & $120.2 \pm 54.8$ \\
No. of eggs/clutch & $55.8 \pm 17.9$ & $45.3 \pm 13.0$ & $51.3 \pm 23.1$ & $59.8 \pm 26.2$ \\
Egg size (TD) (mm) & $0.100 \pm 0.02^{\mathrm{a}}$ & $0.105 \pm 0.03^{\mathrm{a}}$ & $0.125 \pm 0.03^{\mathrm{b}}$ & $0.110 \pm 0.04^{\mathrm{b}}$ \\
\hline
\end{tabular}

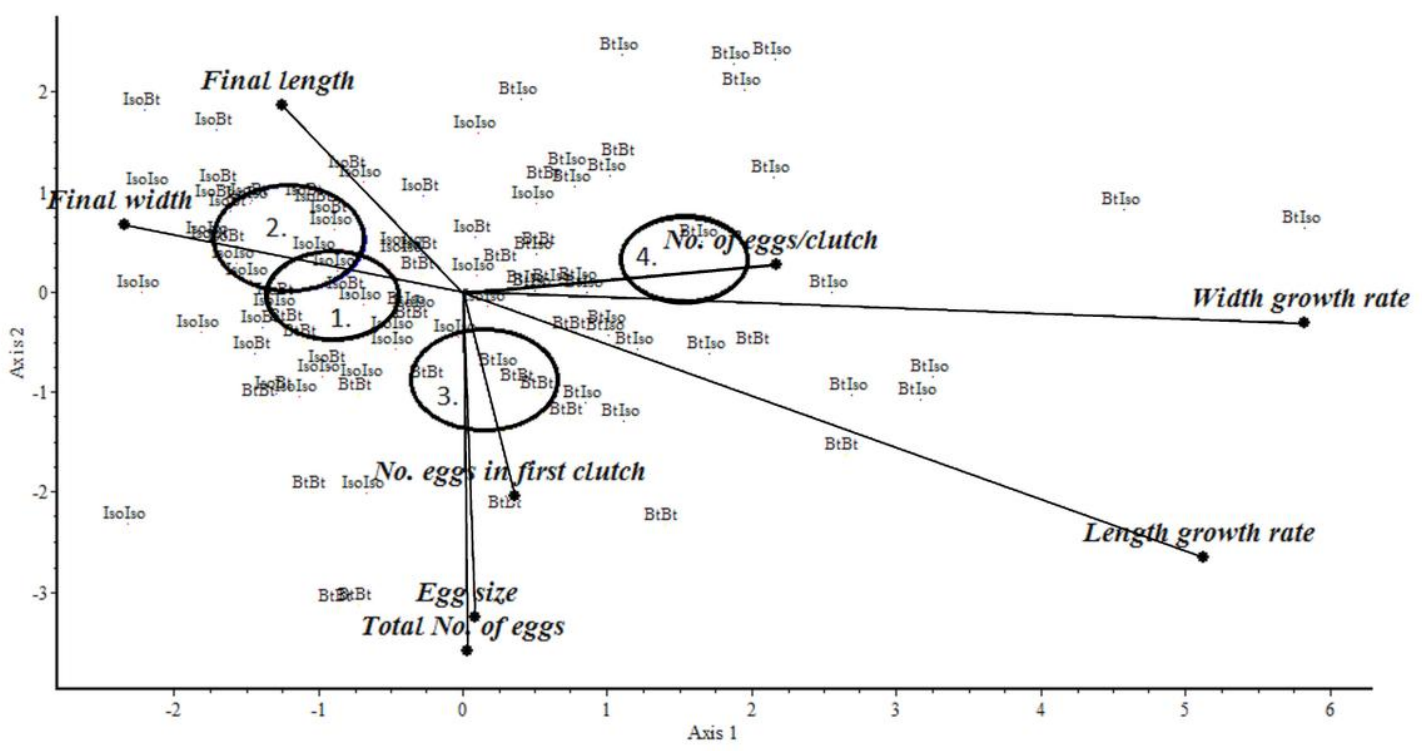

Figure 3. Results of the CVA analysis. Confidence circles are shown. Numbers of treatments are as follows: 1. Isolso, 2. IsoBt, 3. BtBt, 4 BtIso.

The effect of the long-term feeding is demonstrable by comparing data from IsoIso and $\mathrm{BtBt}$ treatments. Three out of nine measured traits showed significant differences between these treatments (Table 1). Both of the length and with growth rate was higher in the case of the BtBt treatment during the investigated period. Besides, collembolans in BtBt treatment laid significantly larger eggs. No other traits differed between the two treatments (Table 1). The mortality of the four treatments was 22, 29, 20 and 28 percent 
in IsoIso, IsoBt, Bt Iso, and BtBt treatment, respectively. No significant differences were detected between these values $(\mathrm{p}=0.231, \mathrm{z}=-1.197)$.

\section{Food change effect}

Changing of food source did not cause significant alteration in any traits measured in the study (Table 1). Neither the food change from Iso to Bt nor vice versa has any statistical difference in life-history traits. However, egg size and total number of eggs correlate negatively each other $(\mathrm{r}=0.41, \mathrm{t}=2.4, \mathrm{p}<0.03$ and $\mathrm{r}=0.32, \mathrm{t}=2.1, \mathrm{p}<0.05$ for IsoBt and BtIso treatments, respectively).

Results of the CVA analysis show differences between population traits (Figure 3). Eigenvalues as a percent of Axis1 and 2 are 78.7 and 16.1, respectively, i.e. the first two axes explain 94.8 percent of the total variance. Both Axis1 and 2 contribute significantly to separation of the groups ( $\operatorname{chi} 2=107.1, \mathrm{df}=24, \mathrm{p}<0.001$ and chi2 $=$ 29.6, df: 14, p $<0.01$ for Axis1 and 2, respectively). Axis1 determines first of all the growth and Axis2 the reproduction of the $F$. candida. The main factors responsible for the separation of all the four groups are final length and width as well as their growth rates. This result coincides with a negative correlation of final size and growth rate of animals, as it was presented before. The traits, "total number of eggs", and "egg size" distinguish between groups, where food change occurred, especially in the case of the BtIso treatment (Figure 3).

The mortality of the four treatments was $22,29,20$ and 28 percent in IsoIso, IsoBt, $\mathrm{Bt}$ Iso, and BtBt treatment, respectively. The alteration of the food did not cause a significant difference in mortality $(\mathrm{p}=0.1109, \mathrm{z}=-1.594)$, but the interaction of the long-term feeding and the food change was significantly associated with mortality $(\mathrm{p}=$ $0.0345, \mathrm{z}=2.114)$.

\section{Discussion}

According to Zwahlen et al. (2003), the Cry1 Ab toxin can persist in the soil up to 2 years. In spite of this fact, a long-term investigation of Cry1 Ab toxin producing maize on soil fauna is very rare. That is why Heckmann et al. (2006) and Székács and Darvas (2013) emphasise the significance this kind of studies.

In our previous investigation with $F$. candida (Bakonyi et al., 2011), we did not find a relationship between elapsed time from the start of feeding on the Bt-maize and a total number of eggs produced by one individual. This trait was affected neither in the present, a longer experiment where similar maize lines were used.

It has long been known that food limitation (Martin, 1987), as well as the quality of the food (Boersma and Kreutzer, 2002), can considerably influence life history traits. According to the results of the present study, two slightly different life-history strategies seem to emerge due to long-term feeding on two qualitatively different food sources. Our populations have been fed for 40-48 generations on either near-isogenic or Btmaize. So many generations may be definitely enough for adaptive changes of lifehistory and adjust to different food sources (Awmack and Leather, 2002; Fricke and Arnqvist, 2007). Probably, as a consequence of accommodation to food, our collembolans in BtBt treatment produced larger eggs than in IsoIso one. Tully and Ferrière (2008) found that there is a positive relationship between egg size and juvenile size, and larger $F$. candida juveniles have improved quality, which means a higher chance to survive and better productivity. Maybe that is why the time until the first 
clutch is shorter (although not significantly) and the body growth rate is higher in BtBt treatment and BtBt collembolans reach their maturity earlier. In the case of the IsoIso treatment, all these traits are changing oppositely. However, the final body size is equal in both treatments. The result of all these events is the differently shaped growth curves of collembolans in IsoIso and BtBt treatments (Figure 4).

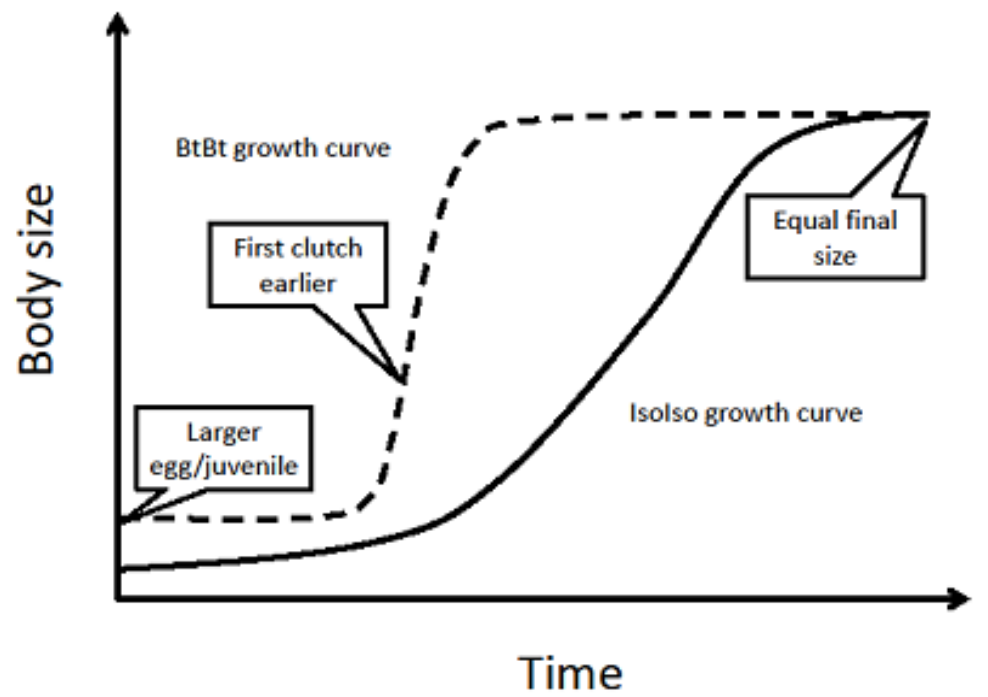

Figure 4. Schematic presentation of results summary. Differences in body length growth of the IsoIso and BtBt treatments is presented.

Based on the results of CVA analysis, it was not a noteworthy consequence if the collembolans from the Iso stock breed were fed with Bt-maize during the experiment. Oppositely, considerable modification in reproduction traits was observable, if collembolans from Bt stock breed were fed with near-isogenic leaf during the experiment. Reproduction of the collembolan in the BtIso treatment becomes more similar to IsoIso and IsoBt treatments than to their original BtBt counterparts. Smaller eggs in the BtIso treatment may be a sign of the favorable food (Tully and Ferrière, 2008).

It is well known that food quality has a significant influence on life-history traits of F. candida (Jørgensen et al., 2008). So, the contrast between the two life-history strategies observed in this experiment may be the results of the different quality of maize leaves used as food. Nitrogen proved to be one of the main factors, which determine reproduction and growth of $F$. candida in several cases (Booth and Anderson, 1979; Leonard and Anderson, 1991; Kaneda and Kaneko, 2002). However, leaf nitrogen and carbon content were similar in maize leaves in our study. That is why nitrogen was probably not responsible for life-history changes detected in our study.

The higher lignin content of MON810 comparing its near-isogenic counterpart is suggesting as a factor, which can decrease digestibility of this Bt-maize by herbivores (Saxena and Stotzky, 2001). However, they investigated the lignin content of stems and not leaves, and lignin content is different in maize stem and leaf (Johnson et al., 2007). In the case of maize leaf, Tarkalson et al. (2008) did not find differences in lignin content of four maize lines (Pioneer 34N44 Bt, Pioneer 34N43, NC+4990 Bt, $\mathrm{NC}+4880$ ). Poerschmann et al. (2005) found marginally higher lignin content in the Bt- 
maize leaf than in its near-isogenic counterpart (Novelis, Valmont Bt and Nobilis, Prelude near-isogenic lines). We did not measure the lignin content of the leaves, so the possible lignin effect remained unanswered. Besides, any undetected factor(s), which influenced $F$. candida food choice (Bakonyi et al., 2006), may also be responsible for alteration in reproductive strategy of the $\mathrm{BtBt}$ and IsoIso treatments.

Previous studies suggest that qualitative differences between $\mathrm{Bt}$ and near-isogenic lines may occur, which explain detected differences of the life-history strategies of the IsoIso and BtBt populations in this study. Our findings are in line with the results of several studies, which revealed life-history adaptation due to food alteration at $F$. candida (Booth and Anderson, 1979; Stam et al., 1996; Tully and Ferrière, 2008).

The exact effect of Cry toxins on the population biology of $F$. candida and other insect species remained an unresolved issue till now. The central problem is that Cry toxins are embedded in the matrix of plant cell cytoplasm, and their effect could be correctly interpreted only in this context. If pure Cry toxins were examined in any experiments, no effect was found (Sims and Martin, 1997; Yu et al., 1997; Galbraith et al., 2015; Yang et al., 2015). It does not mean that possible harm of the toxin could be excluded with confidence because potentiating effects has never been tested yet. However, it remains questioning, whether such a test developable or not. Moreover, if whole Bt-plant or any plant parts was tested in a study, then the current experimental methods did not separate the only effect of any cell component (including Cry toxin) from the other. New methodologies are required in order solving this problem.

Using functional traits to predict responses to environmental changes is in the focus of several contemporary soil ecological studies (Hedde et al., 2012; Salmon et al., 2014). Collembolan functional traits were involved as markers of biodiversity decline (Vandewalle et al., 2010), climate change (Makkonen et al., 2011; Bokhorst et al., 2012), forest fire (Malmström, 2012) and urbanisation (Santorufo et al., 2014). Moreover, Hawes et al. (2009) applied this approach in order to evaluate effects of genetically modified herbicide-tolerant crops on functional groups of soil invertebrates. It was found that this method is suitable for monitoring effects of the new crops introduction in an area. Correspondingly, our result indicates that $F$. candida egg size and growth are appropriate functional traits for such monitoring work.

\section{Conclusions}

Long-term (40-48 generation) feeding of $F$. candida on Cry1 Ab toxin producing maize (Mon810, YieldGard $®$ ) causes considerable differences in this species compared to the treatment group which was fed with near-isogenic maize. Change of life-history parameters causes a difference in the growth curve of animals. On the other hand, a shift in food source (change from Bt to Iso maize) may initiate changes in reproduction. This shift is a quick process, which is observable even in one generation, as it is proved in this experiment.

Acknowledgements. Contribution in the laboratory work is acknowledged to I. Surman and M. Weisz. Funding: This research did not receive any specific grant from funding agencies in the public, commercial, or not-for-profit sectors. 


\section{REFERENCES}

[1] Arias-Martín, M., García, M., Luciáñez, M. J., Ortego, F., Castañera, P., Farinós, G. P. (2016): Effects of three-year cultivation of CrylAb-expressing Bt maize on soil microarthropod communities. - Agriculture, Ecosystems and Environment 220: 125-134.

[2] Awmack, C.S., Leather, S.R. (2002): Host plant quality and fecundity in herbivorous insects. - Annual Review of Entomology 47: 817-44.

[3] Bai, Y., Yan, R., Ke, X., Ye, G., Huang, F., Luo, Y., Cheng, J. (2011): Effects of transgenic Bt rice on growth, reproduction, and superoxide dismutase activity of Folsomia candida (Collembola: Isotomidae) in laboratory studies. - Journal of Economic Entomology 104: 1892-1899.

[4] Bakonyi, G., Dolezsai, A., Mátrai, N., Székács, A. (2011): Effects of consumption of Btmaize (MON 810) on the Collembolan Folsomia candida, over multiple generations: a laboratory study. - Insects 2: 243-252.

[5] Bakonyi, G. (1983): Effects of Folsomia candida (Collembola) on the microbial biomass in a grassland soil. - Biology and Fertility of Soils 7: 138-141.

[6] Bakonyi, G., Szira, F., Kiss, I., Villányi, I., Seres, A., Székács, A. (2006): Preference tests with collembolas on isogenic and Bt-maize. - European Journal of Soil Biology 42: 132-135.

[7] Birch, A.N.E., Griffiths, B. S., Caul, S., Thompson, J., Heckmann, L. H., Krogh, P. H. (2007): The role of laboratory, glasshouse and field scale experiments in understanding the interactions between genetically modified crops and soil ecosystems : A review of the ECOGEN project. - Pedobiologia 51: 251-260.

[8] Bokhorst, S., Phoenix, G. K., Bjerke, J. W., Callaghan, T. V., Huyer-Brugman, F., Berg, M. P. (2012): Extreme winter warming events more negatively impact small rather than large soil fauna: shift in community composition explained by traits not taxa. - Global Change Biology 18: 1152-1162.

[9] Boersma, M., Kreutzer, C. (2002): Life at the edge: is food quality really of minor importance at low quantities? - Ecology 83: 2552-2561.

[10] Booth, R.G., Anderson, J.M. (1979): The influence of fungal food quality on the growth and fecundity of Folsomia candida (Collembola: Isotomidae). - Oecologia 38: 317-323.

[11] Broza, M., Pereira, R.M., Stimac, J.L. (2001): The nonsusceptibility of soil Collembola to insect pathogens and their potential as scavengers of microbial pesticides. - Pedobiologia 45: 523-534.

[12] Clark, B.W., Coats, J.R. (2006): Subacute effects of Cry1Ab Bt corn litter on the earthworm Eisenia fetida and the springtail Folsomia candida. - Enviromental Entomology 35: 1121-1129.

[13] Comas, C., Lumbierres, B., Pons, X., Albajes, R. (2014): No effects of Bacillus thuringiensis maize on nontarget organisms in the field in southern Europe: a metaanalysis of 26 arthropod taxa. - Transgenic Research 23: 135-143.

[14] Fountain, M.T., Hopkin, S.P. (2005): Folsomia candida (Collembola): a "standard" soil arthropod. - Annual Review of Entomology 50: 201-222.

[15] Fricke, C., Arnqvist, G. (2007): Rapid adaptation to a novel host in a seed beetle (Callosobruchus maculatus): the role of sexual selection. - Evolution 61: 440-454.

[16] Galbraith, D.A., Yang, X., Lastro, E., Yi, S., Grozinger, C. (2015): Parallel epigenomic and transcriptomic responses to viral infection in honey bees (Apis mellifera). - PloS Pathogens 11: p.e1004713.

[17] Goto, H.E. (1960): Simple techniques for the rearing of Collembola and a note on the use of a fungistatic substance in the cultures. - Entomologists' Monthly Magazine 96: 138-140.

[18] Hawes, C., Haughton, A. J., Bohan, D. A., Squire, G. R. (2009): Functional approaches for assessing plant and invertebrate abundance patterns in arable systems. - Basic and Applied Ecology 10: 34-42.

[19] Heckmann, L., Griffiths, B. S., Caul, S., Thompson, J., Pusztai-Carey, M., Moar, W. J., Andersen, M. N., Henning, P. (2006): Consequences for Protaphorura armata 
(Collembola: Onychiuridae) following exposure to genetically modified Bacillus thuringiensis $(\mathrm{Bt})$ maize and non- Bt maize. - Environmental Pollution 142: 212-216.

[20] Hedde, M., Van Oort, F., and Lamy, I. (2012): Functional traits of soil invertebrates as indicators for exposure to soil disturbance. - Environmental Pollution 164: 59-65.

[21] Hönemann, L., Zurbrügg, C., Nentwig, W. (2008): Effects of Bt-corn decomposition on the composition of the soil meso- and macrofauna. - Applied Soil Ecology 40: 203-209.

[22] Hyams, D.G. (2010): CurveExpert software. - http://www.curveexpert.net

[23] James, C. (2015): 20th Anniversary (1996 to 2015) of the global commercialization of biotech crops and biotech crop highlights in 2015. - ISAAA Brief No. 51, ISAAA: Ithaca, NY.

[24] Jepson, P.C., Croft, B.A., Pratt, G.E. (1994): Test systems to determine the ecological risks posed by toxin release from Bacillus thuringiensis genes in crop plants. - Molecular Ecology 3: 81-89.

[25] Johnson, J.M.F., Barbour, N.W., Weyers, S.L. (2007): Chemical composition of crop biomass impacts its decomposition. - Soil Science Society of America Journal 71: 155-162.

[26] Jørgensen, H.B., Hedlund, K., Axelsen, J.A. (2008): Life-history traits of soil collembolans in relation to food quality. - Applied Soil Ecology 38: 146-151.

[27] Kaneda, S., Kaneko, N. (2002): Influence of soil quality on the growth of Folsomia candida (Willem) (Collembola). - Pedobiologia 439: 428-439.

[28] Leonard, M.A., Anderson, J.M. (1991): Growth dynamics of Collembola (Folsomia candida) and a fungus (Mucor plumbeus) in relation to nitrogen availability in spatially simple and complex laboratory systems. - Pedobiologia 35: 163-173.

[29] Makkonen, M., Berg, M. P., Van Hal, J. R., Callaghan, T. V., Press, M. C., Aerts, R. (2011): Traits explain the responses of a sub-arctic Collembola community to climate manipulation. - Soil Biology and Biochemistry 43: 377-384.

[30] Malmström, A. (2012): Life-history traits predict recovery patterns in Collembola species after fire: a 10 year study. - Applied Soil Ecology 56: 35-42.

[31] Martin, T.E. (1987): Food as a limit on breeding birds: a life-history perspective. Annual Review of Ecology and Systematics 18: 453-87.

[32] Marvier, M., McCreedy, C., Regetz, J., Kareiva, P. (2007): A meta-analysis of effects of Bt cotton and maize on nontarget invertebrates. - Science 316: 1475-1477.

[33] Podani, J. (1993): SYN-TAX-Pc. , 53.

[34] Poerschmann, J, Gathmann, A., Augustin, J., Langer, U., Górecki, T. (2005): Molecular composition of leaves and stems of genetically modified $\mathrm{Bt}$ and near-isogenic non-Bt maize - characterization of lignin patterns. - Journal of Environmental Quality 34: $1508-1518$.

[35] R Core Team (2012): R: A language and environment for statistical computing, - Vienna, Austria: R Foundation for Statistical Computing. Available at: https://www.r-project.com

[36] Romeis, J., Battini, M., Bigler, F. (2003): Transgenic wheat with enhanced fungal resistance causes no effects on Folsomia candida (Collembola: Isotomidae). Pedobiologia 47: 141-147.

[37] Rusek, J. (1998): Biodiversity of Collembola and their functional role in the ecosystem. Biodiversity and Conservation 7: 1207-1219.

[38] Salmon, S., Ponge, J. F., Gachet, S., Deharveng, L., Lefebvre, N., Delabrosse, F. (2014): Linking species, traits and habitat characteristics of Collembola at European scale. - Soil Biology and Biochemistry 75: 73-85.

[39] Santorufo, L., Cortet, J., Arena, C., Goudon, R., Rakoto, A., Morel, J. L., Maisto, G. (2014): An assessment of the influence of the urban environment on collembolan communities in soils using taxonomy- and trait-based approaches. - Applied Soil Ecology 78: 48-56.

[40] Saxena, D., Stotzky, G. (2001): Bt corn has a higher lignin content than non-Bt corn. American Journal of Botany 88: 1704-1706.

[41] Schneider, C.A., Rasband, W.S., Eliceiri, K. (2012): NIH Image to ImageJ: 25 years of image analysis. - Nature Methods 9: 671-675. 
[42] De Schrijver, A., Devos, Y., De Clercq, P., Gathmann, A., Romeis, J. (2016): Quality of laboratory studies assessing effects of Bt-proteins on non-target organisms: minimal criteria for acceptability. - Transgenic Research 25: 395-411.

[43] Sims, S.R., Martin, J. (1997): Effect of the Bacillus thuringinesis insecticidal proteins CryIA(b), CryIA(c), CryIIA, and CryIIIA on Folsomia candida and Xenylla grisea (Insecta: Collembola). - Pedobiologia 41: 412-416.

[44] Stam, E.M., Leemkule, M. A., Ernsting, G. (1996): Trade-offs in the life history and energy budget of the parthenogenetic collembolan Folsomia candida (Willem). Oecologia 107: 283-292.

[45] Székács, A., Lauber, E., Juracsek, J., Darvas, B. (2010): Cry1Ab toxin production of MON 810 transgenic maize. - Environmental Toxicology and Chemistry / SETAC 29: 182-90.

[46] Székács, A., Lauber, É., Takács, E., Darvas, B. (2010): Detection of Cry1 Ab toxin in the leaves of MON 810 transgenic maize. - Analytical and Bioanalytical Chemistry 396: 2203-2211.

[47] Székács, A., Darvas, B. (2013): Comparative aspects of Cry toxin usage in insect control. - In: Ishaaya, I., Palli, S. R., Horowitz, A. R. (eds.) Advanced Technologies for Managing Insect Pests. Springer.

[48] Tarkalson, D.D., Kachman, S. D., Knops, J. M., Thies, J. E., Wortmann, C. S. (2008): Decomposition of Bt and non-Bt corn hybrid residues in the field. - Nutrient Cycling in Agroecosystems 80: 211-222.

[49] Tully, T., D’Haese, C. A., Richard, M., Ferrière, R. (2006): Two major evolutionary lineages revealed by molecular phylogeny in the parthenogenetic collembola species Folsomia candida. - Pedobiologia 50: 95-104.

[50] Tully, T., Ferrière, R. (2008): Reproductive flexibility: genetic variation, genetic costs and long-term evolution in a collembola. - PloS one 3: p.e3207.

[51] Vandewalle, M., De Bello, F., Berg, M. P., Bolger, T., Dolédec, S., Dubs, F., .Feld, C. K., Harrington, R., Harrison, P.A., Lavorel, S., Da Silva, P. M., Moretti, M., Niemela, J., Santos, P., Sattler, T., Sousa, J.P., Sykes, M.T., Vanbergen, A.J., Woodcock, B.A. (2010): Functional traits as indicators of biodiversity response to land use changes across ecosystems and organisms. - Biodiversity and Conservation 19: 2921-2947.

[52] Yang, Y., Chen, X., Cheng, L., Cao, F., Romeis, J., Li, Y., Peng, Y. (2015): Toxicological and biochemical analyses demonstrate no toxic effect of Cry1C and Cry2A to Folsomia candida. - Scientific Reports 5: p.15619.

[53] Yu, L., Berry, R.E., Croft, B.A. (1997): Effects of Bacillus thuringiensis toxins in transgenic cotton and potato on Folsomia candida (Collembola: Isotomidae) and Oppia nitens (Acari: Orbatidae). - Journal of Economic Entomology 90: 113-118.

[54] Yuan, Y., Xiao, N., Krogh, P. H., Chen, F., Ge, F. (2013): Laboratory assessment of the impacts of transgenic Bt rice on the ecological fitness of the soil non-target arthropod, Folsomia candida (Collembola: Isotomidae). - Transgenic Research 22: 791-803.

[55] Zhang, B., Yang, Y., Zhou, X., Shen, P., Peng, Y., Li, Y. (2017): A laboratory assessment of the potential effect of Cry1 Ab and Cry2Aj containing Bt maize pollen on Folsomia candida by toxicological and biochemical analyses. - Environmental Pollution 222: 94-100.

[56] Zwahlen, C., Hilbeck, A., Nentwig, W. (2003): Degradation of the Cry1Ab protein within transgenic Bacillus thuringiensis corn tissue in the field. - Molecular Ecology 12: 765-775.

[57] Zwahlen, C., Hilbeck, A., Nentwig, W. (2007): Field decomposition of transgenic Bt maize residue and the impact on non-target soil invertebrates. - Plant and Soil 300: 245-257. 